\title{
An Error Analysis of English Attributive Clauses by Non-English Major College Students
}

\author{
Shizhong Zhao \\ School of Foreign Languages, Shenyang Jianzhu University, Shenyang, 110168, China \\ 13940188902@163.com
}

Key words: error analysis; attributive clause; non-English major college students

\begin{abstract}
Set in the framework of error analysis theory, this article focuses on the analysis of errors in English attributive clause committed by college students, aiming at finding what kinds of errors non-English major college students often commit, why students commit these errors. The findings suggest that, the classifications of errors are wrong use of relative words, relative adverbs. Further study shows that, students commit these errors because of emphasizing language form too much, lack of systematic grammar knowledge, necessary vocabulary, language transfer and over-generalization. From the research, teachers should teach grammar exactly and make students know each grammar rules exactly. In the process of learning English attributive clause, teachers should also give students clear instruction on grammar learning. Through revealing the categories and reasons of committing errors, it is hoped that this study can help non-English major college students learn English attributive clause better.
\end{abstract}

\section{Introduction}

Error analysis, as a branch of applied linguistics, has become an important component of second language learning and acquisition. Error analysis sets up on the basis of the theories on foreign language acquisition creatively. This method states that the process of learning a foreign is the same as learning the native language, which is a creative hypothesis. Language errors can show students' acquisition degree of foreign language rules. In the process of second language acquisition, it is unavoidable for learners to commit errors and the study of learners' errors has gradually attracted great attention of English teachers. This study is based on the theory of Error Analysis (EA) with approaches of quantitative analysis in combination with qualitative discussions. This research attempts to find out the categories of English attributive clause errors committed by non-English major college students, and why students commit these errors. It is hoped that this study can help college students learn English attributive clause better.

\section{Error Analysis Theory and its Procedures}

Error Analysis (EA) theory is developed within Contrastive Analysis (CA). For the purpose of acquiring a more effective method to solve the learning and teaching problems of foreign or second language, error analysis sets up on the basis of the theories on foreign language acquisition creatively. This method makes a brief belief that the process of learning a foreign is the same as learning the native language, which is a creative hypothesis. And language errors can show students' acquisition degree of foreign language rules. Compared with contrastive analysis, error analysis tries to comprehend and master the learning process through learning product aiming to help and promote second language acquisition. The research on error analysis begins from Corder (1974) [1], who holds that for learners' errors, it is not wise for us to reject them simply. Adversely, learners' errors provide useful information for language researchers and teachers about sample of second language acquisition. It also reflects that learners try to apply rules into the target language and try to find out the system of the target language. Many valuable information and learning ways can be gained. Error analysis is an important method of studying different types of errors when learning and teaching the foreign or second language, which makes language errors into categories aiming at different stages of learners and analyzes their causes with the purpose of urging language 
teachers treat errors scientifically and reminding learners avoid errors consciously. According to Corder (1974), five steps in error analysis research.

\section{(1) Error collection}

The first step in error analysis is to decide how to collect language learners' errors samples from their linguistic production both in speaking or writing as well as in listening. In this process, two issues should be considered. One is that the learners' language should reflect natural, spontaneous language use; the other is about the method of collecting samples of learners' language. There are two methods: cross-sectional method (at a single point in time) and longitudinal method (successive points over a period of time).

\section{(2) Error identification}

After collecting the samples of language errors, the identification of errors should be carried out by the following standard of communication and written language. Sentences should be grammatically well-formed and appropriate in specific situational context. That should be grammatically well-formed and appropriate in specific situational context. That is to identify errors that we should compare the sentences learners produce with what is regarded as the normal or correct sentences in the target language. If they are the same, there are not any errors, otherwise, errors will appear.

\section{(3) Error classification}

After identifying all errors, we should describe and classify the errors into different types. Several methods can be used, one of the simplest way is to classify errors based on linguistic categories (for example, the grammatical category and the lexical category), and this type is also associated with the traditional pedagogic purposes of error analysis. The other way is to use surface structure taxonomy. This type emphasizes the ways surface structures are altered by means of omission, addition, disordering and malformation.

\section{(4) Error explanation}

This step aims at finding the cause and source of errors, which are to account for why an error is made. It aims at finding a good correction strategy. This step is the most important step for second language acquisition because it involves and establishes the process responsible for second language acquisition. Most researchers attempt to provide a psychological explanation. The sources of errors are closely related with the classifications of errors, which result in different research results and explanations of errors. Taylor thinks "error source can be psycholinguistic, sociolinguistic, epistemic, or may reside in the discourse structures" [2]. Selinker [3] describes five major processes leading to errors in second language learning: language transfer, strategies of second language learning, strategies of second language communication, transfer of training overgeneralization target language linguistic material.

\section{(5) Error evaluation}

Error analysis aims at helping teachers improving their teaching and helping learners learning well a second language, therefore, it is of great necessity to evaluate errors. Some of the errors may be required more serious than others because these errors are more likely to interfere with the learners' intelligibility of what they say or write. Teachers should emphasize their attention on the errors. It can give teachers a clear guide to take a proper strategy.

Corder (1974) maintains that the learners' errors are invaluable to the study of the process of language learning. He first states the significance of errors in the process of language learning and teaching. He thinks errors can be important: they provided researchers with the evidence that what the language was learnt; they also provide researchers with a device that which the learners have discovered the target language rules. Therefore, analyzing and studying learners' errors can lay a fundament for language teaching.

Error analysis theory has been applied in many studies to analyze different types of discourse. For example, it is used to explore the recording students' English utterance and then makes a survey on it [4]. Chen and Wang [5] did a study on the integration of current error classification of various sorts. Geng and Ma [6] analyze the writing errors committed by non-English major students, 
pointing out the typical errors and the reason why making this kind of mistakes from the aspect of word, sentence and passage.

Through researches on error analysis both abroad and at home, we can learn that the studies of error analysis are mainly on the theory study and it appears in a very early time. The studies abroad have more advantages that that at home. Comparing with the researchers abroad, we do not have any special works on error analysis at home. Scholars do not make a systematic theory study as those foreign scholars; they only simply introduce the error analysis theory and the summary of others. Many potential factors are ignored those researchers, such as the subjects English level, taking these into consideration, we should make a deeper discussion about the reason why these errors occur in the process of the acquisition of English attributive clause. The researchers at home mainly analyze the writing tasks and questionnaires to collect data. However, the methods that foreign scholars use more variables, they not only collect the writing tasks but also collect the information about spoken English. This thesis aims to make a close combination between error analysis theory and English attributive clause. Learners have much more work to do to enrich the study of attributive clause and errors. This thesis makes a combination between English attributive clause and error analysis theory.

\section{Research Methodology and Tools}

This thesis aims to find out the real situation that college students commit errors in the process of using English attributive clause. The author designs a set of examination papers with 50 questions, which includes four parts: single choices, filling in he blanks, correcting sentences' errors and combining two sentences together using English attributive clause. According to the process of error analysis proposed by Corder (1974), five main steps are carried out to discuss errors committed by college students.

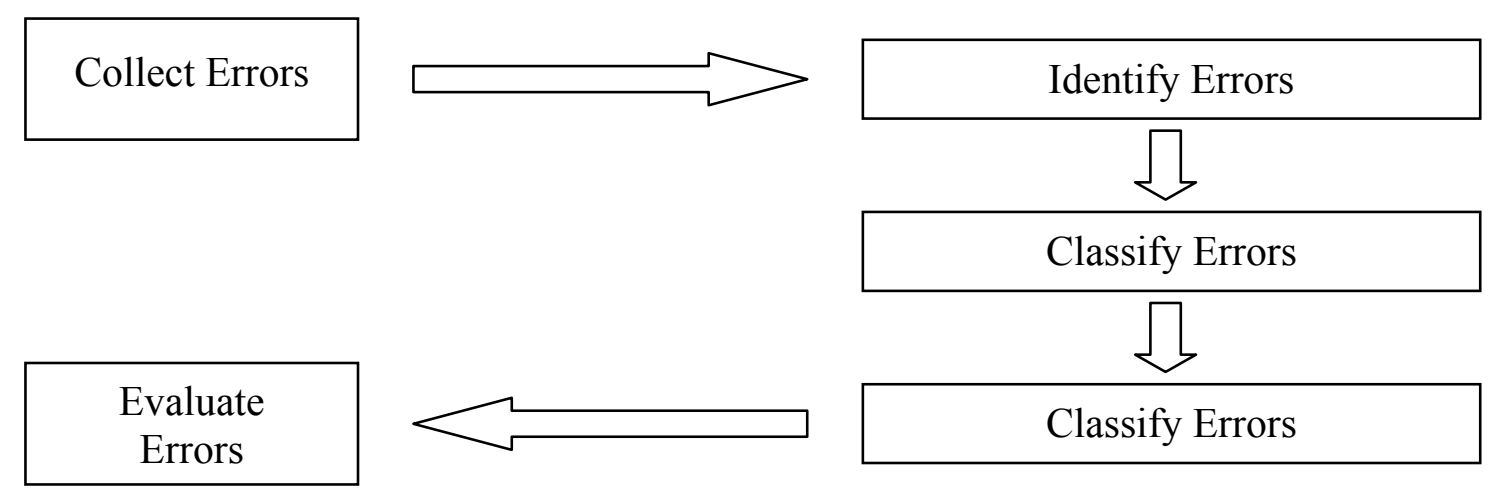

Fig. 1. Procedures of error analysis

The first step is to collect data. At the end of the term, the author requests two teachers who teach different classes to cooperate with the author in the process of this exam. Two teachers assign 110 students of their own. The second step is to identify students' errors in their papers and calculate students' final score. The third step is to classify students' errors. The fourth step is to explain errors. The last step in this research is to evaluate errors. Through the errors proportion results and questionnaires results, the author gets a clear understanding of students' errors.

In all, both qualitative and quantitative methods are used in this research. Qualitative method is mainly used to achieve a theoretical insight about Chinese non-major English students' acquisition of attributive clauses in term of second language acquisition. Quantitative research method is employed to have a clear picture of the types and degrees of the problems of students' learning of attributive clauses, and further to support the theoretical reflection.

It is should be pointed out that data collected are all authentic students' test performances, and only a small proportion are cited from reference books. For the analysis of some instances, the author has consulted three native English speakers in Shenyang Jianzhu University. 


\section{Results and Discussion}

\section{Classification of errors}

By analyzing and collecting the errors from the papers that students did last term, the author discovers that the errors of students are mainly from the use of relative pronouns, relative adverbs, redundant components and so on.

Table 1. Wrong Use of Relative Pronouns

\begin{tabular}{c|c|c}
\hline Relative pronouns & Error Quantity & Proportion (\%) \\
\hline Which/that & 47 & 42.7 \\
\hline Who/whom & 44 & $40 \%$ \\
\hline Whose/as & 82 & 74.5 \\
\hline
\end{tabular}

As we can see from Table 1, there are five types of English attributive clause errors, in which, we can clearly get a glimpse of whether students master relative pronouns. From the test, the average error rate of using "which" and "that" is $42.7 \%$. That shows that over half students master the use of "which". For example,

The boy likes the meal which his other did. / One was a violent thunderstorm, the worst I had ever seen, which obscured my objective. [6].

In English attributive clause, if the antecedents refer to persons, we use the relative pronoun "who/whom". From the table above, the error rate is $40 \%$, few students commit errors when they use "who/whom". For example,

The man who/whom I talked just now is my new friend. / There is a girl who wants to invite you to have dinner together.

As for the use of "whose/as", we know that most students fail to use them correctly, the average rate is over $70 \%$. For example,

That is a girl whose mother is over there. / He isn't such a person as he used to be.

Table 2. Wrong Use of Relative Adverbs

\begin{tabular}{c|c|c}
\hline Relative Adverbs & Frequencies & Proportion (\%) \\
\hline Where & 51 & 46.3 \\
\hline When & 43 & 39.1 \\
\hline why & 48 & 43.6 \\
\hline
\end{tabular}

As shown in Table 2, most students can master the use of relative adverbs well. Only few students still commit errors in the process of using "where/when/why". For example,

Tianjin is a city where I used to work. / I can't forget the day when he wants abroad. / I didn't know the reason why he didn't come.

In English attributive clause, the functions of relative word are connecting and leading the subordinate clause, replacing the antecedent in principal clause, or even a part or the whole sentence of the principal clause, serving as a component in the subordinate clause [7]. Relative words in attributive clause can refer to antecedent and the antecedent cannot appear in the subordinate clause again. For example,

It is a pretty toy that I bought it yesterday. (wrong)

It is a pretty toy that I bought yesterday. (correct)

\section{Causes of Errors}

According to error analysis theory, the destination of studying students' errors is to fid out the reason why students commit errors and find out proper and reasonable ways and solutions to help students reduce errors and improve the teaching effect and the second language acquisition. According to the tests results, the causes of errors in the process of learning English attributive clause will be listed as follows. 
(1) Emphasizing language form too much. When students learn a foreign language, students are always focusing their attention to the language form and neglecting the reality usage of a language. They only want to make the sentence in the correct order and sequence and neglect the real meaning of all language and the language situation [8].

(2) Lack of systematic grammar knowledge and necessary vocabulary. By conducting personal conversations with college students, most students thinks that they commit errors because they do not have a good understanding of the attributive clause grammar rules and they also claim that they do not remember enough vocabulary. Students cannot master the grammar well and commit errors because of the incompletely master of grammar and vocabulary.

(3) Language transfer. Dai points out the research of language transfer in the process of Chinese learners' acquisition English should be paid more attention to. Language transfer is one of the main causes that cause errors in the second language acquisition.

(4) Over-generalization. Over-generalization refers to language learners in both first and second language acquisition have been observed to commit errors like "comed", "had better to do", which can be explained as extensions of some general rule to items not covered by this rule in the target language.

\section{Conclusion}

For second language acquisition, the English attributive clause is a difficult issue for students and teachers to study and it becomes a heated topic. Even though the relative clause is studied in various aspects, the author chooses the English attributive clause errors committed by non-English major college students in China. Having carried out the designed research, the author makes a detailed analysis and discussion. By analyzing the data, the author finds that the errors that committed by non-English major college students mainly lie in the wrong use of relative pronouns and the main reason why students commit errors on this aspect. And the cause why students commit errors is also analyzed with reference to the learners' linguistic proficiency. Because of the limited time, energy, and the scholar ability, this paper is far from a perfect paper and still needs further modification, but on the whole, the research questions are correspondingly answered.

\section{Acknowledgement}

This paper has been sponsored by Liaoning Social Science Planning Fund Program (No. L12DYY026) of China.

\section{References}

[1] S. P. Corder, "The Significance of Learners' Errors", International Reviews of Applied Linguistics, no. 4, pp. 161-169, 1967.

[2] G. Taylor, Fundamental Concepts of Language Teaching. Oxford: Oxford Uiversity Press, 1988.

[3] L. Selinker, "Interlanguage", International Review of Applied Linguistics, no. 10, pp. 209-231, 1972.

[4] J. Scrievener, Learning and Teaching. Oxford: Macmillan, 2013.

[5] Z. L. Chen, H. Y. Wang, "A Syntactic Analysis of the Differences between Relative Clauses Introduced by That and Wh- Words", Modern Foreign Languages, vol. 29, no. 4, pp. 346-353, 2006.

[6] Z. Geng, H. F. Ma, "The Translation of English Attributive Clause from Cognitive-Functional Perspective", Shanghai Journal of Translators, no. 1, pp. 42-45, 2015.

[7] L. M. Song, X. L. Dong, "Reform and Exploration of English Grammar Teaching in Senior High School", Theory and Practive of Education, vol. 35, no. 23, pp. 58-60, 2015. 
[8] Wei, Y. \& L. Lei. "Lexical Bundles in the Academic Writing of Advanced Chinese EFL learners", RELC Journal, vol. 146, no. 42, pp. 155-166, 2011. 